\title{
Derived environment effects and logarithmic perception
}

\author{
Benjamin Storme \\ Paris 8 / CNRS
}

\section{Introduction}

1.1 The problem Phonologically-derived environment effects (henceforth, PDEEs) describe patterns where a phonological process $\mathrm{P}$ applies only if accompanied by another phonological process P' (Kiparsky, 1973, 1993). PDEEs can be illustrated with Campidanian Sardinian phrase-level lenition, as described by Bolognesi (1998). In Campidanian Sardinian, lenition applies in word-initial position only if accompanied by voicing: intervocalic lenition applies to underlyingly voiceless stops $/ \mathrm{p} \mathrm{k} /$ voiced through intervocalic voicing (1-a), but not to underlyingly voiced stops $/ \mathrm{b} \mathrm{d} \mathrm{g/} \mathrm{(1-b).}{ }^{1}$ The pattern is described as productive by Bolognesi (1998).

(1) Campidanian Sardinian lenition (Bolognesi 1998:30-40)

a. Word-initial voiceless stops are voiced and lenited intervocalically

/kuat:ru/ 'four' [kuat:ru]

[de yuat:ru] 'of four'

b. Word-initial voiced stops are not lenited intervocalically

/goma/ 'rubber' [goma]

[de goma] 'of rubber'

PDEEs are known to be challenging patterns for both rule-based phonology (SPE; Chomsky \& Halle 1968) and classical Optimality Theory (OT; Prince \& Smolensky 1993). In SPE, a rule of intervocalic lenition ordered after a rule of intervocalic voicing will lenite both underlying $/ \mathrm{b} \mathrm{d} \mathrm{g/and} / \mathrm{p} \mathrm{t} \mathrm{k} /$, if no further condition is imposed. In classical OT, the ranking that derives lenition of intervocalic voiceless stops $\left(* \mathrm{VC}_{\text {[-cont] }} \mathrm{V} \gg\right.$ Ident(cont)) will also derive lenition of underlying voiced stops. In both cases, additional machinery is needed in order to distinguish phonologically-derived environments, in which lenition applies, and nonderived environments, in which lenition does not apply. Various proposals have been made to solve this problem including Kisseberth (1972), Kiparsky (1993), Burzio (2000), McCarthy (2003), Wolf (2008), and Hayes \& White (2015) among others.

This paper focuses on yet another problem that PDEEs raise. This problem is specific to theories assuming a preference for minimal input-output changes in phonological grammars, e.g. theories like OT that hold that there is a pressure for the output to be faithful to the input. PDEEs may give rise to alternations called 'saltations' (White, 2013, 2014; Hayes \& White, 2015), i.e. alternations where an underlying string leaps over an intermediary form and this intermediary form does not alternate. In Campidanian Sardinian, the saltatory alternation involving stops in word-initial position is depicted in (2) for velars: underlying / $\mathrm{k} /$ goes to [y] leaping over [g] whereas underlying $/ \mathrm{g} /$ is mapped to itself.

Campidanian Sardinian lenition as saltation

Context: word-initial position between vowels

* I would like to thank Edward Flemming, Donca Steriade, Michael Kenstowicz, Adam Albright, the participants in PhoNE 2017 and the participants in AMP 2017 for helpful comments on this project. A more extended version of this work can be found in my 2017 MIT dissertation Perceptual sources for closed-syllable vowel laxing and derived environment effects.

1 Voicing plus lenition also applies to underlyingly voiceless stops between a vowel and [r], e.g. /siu trintaduzu/ [s:uðrintaduzu] 'the thirty-two'. 


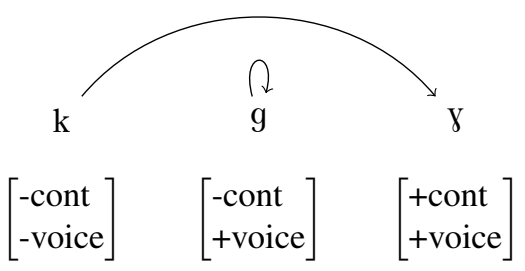

Saltations have been argued to represent a challenge for the hypothesis that phonological grammars only make the smallest input-output change that is required to solve a phonotactic problem. This hypothesis is central in faithfulness-based theories of phonology, and in particular in Steriade's (2009) P-map (perceptibility-map) theory (White, 2013; Hayes \& White, 2015). In Steriade's theory, the P-map represents the knowledge that speakers have about the similarity between sounds in a given phonological context. Learners and speakers use this knowledge to establish a priori rankings of the faithfulness constraints in a way that minimizes deviations from the input in response to markedness constraints. Grammars constrained by the P-map fail to derive PDEEs because if they allow large input-output changes (e.g. $/ \mathrm{k} / \rightarrow$ [y]) then they also allow strictly smaller changes (e.g. /g/ $\rightarrow$ [y]). In response, Hayes and White (2015) propose that PDEEs are not P-map compliant and that the P-map is only a soft bias.

1.2 Proposal This paper proposes a theory reconciling the analysis of PDEEs with the hypothesis of a strong preference for minimal input-output changes. The proposal is based on the idea that a feature change might be less noticeable in the context of another feature change, provided that the distance between the input and the output is perceived logarithmically (cf. the Weber-Fechner law). The intuition behind this proposal can be made concrete with an example from the perception of geographical distance: a distance of three miles seems shorter if I have already traveled 100 miles than if I have only traveled one mile. Applied to Campidanian Sardinian, this translates as follows: lenition is less noticeable in the context of a change in voicing. This is illustrated in Figure 1, where the relation between the input-output distance and its perception is assumed to be logarithmic. The same lenition is perceived as smaller in case it is preceded by voicing (Figure 1b) than in case it is not preceded by voicing (Figure 1a).

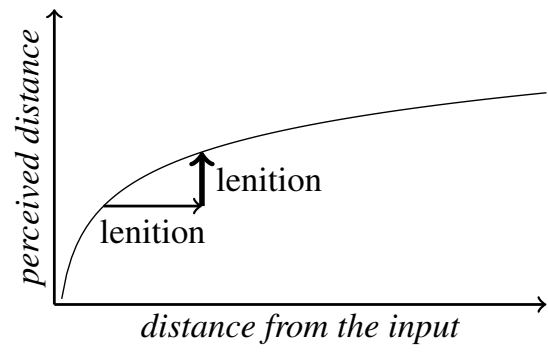

(a) Lenition without voicing

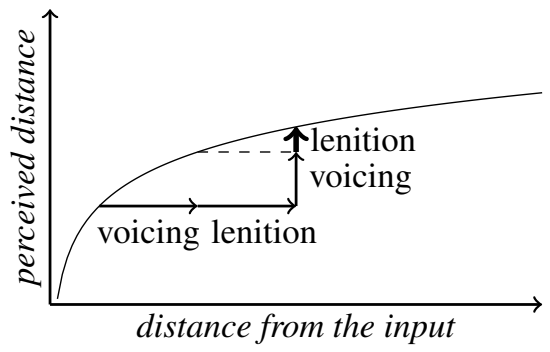

(b) Lenition with voicing

Figure 1: The perception of input-output changes: lenition is less noticeable in the context of a voicing change (Figure 1b) than alone (Figure 1a).

1.3 Outline Section 2 shows how this proposal can be implemented in OT using local conjunctions of faithfulness constraints : these constraints penalize a feature change differently depending on whether or not another feature in the same domain has been changed. This will allow for a given feature change (e.g. lenition) to be considered as a smaller violation of faithfulness if it is independently accompanied by another feature change (e.g. voicing), thus solving the paradox that PDEEs raise for theories like the P-map. Section 3 shows how this proposal makes it possible to constrain in a principled way the features that interact in PDEEs and the domain of this interaction, and therefore to provide a restrictive account of the typology of PDEEs. 


\section{Grammatical implementation}

In order to distinguish the violation of faithfulness to continuancy in the context of a voicing change vs. in the absence of a voicing change in the same segment, I propose to split Ident(cont) into two contextsensitive constraints. One of them penalizes a change in continuancy if this change is not accompanied by a change in voicing in the same segment (3-a). The other constraint penalizes a change in continuancy if this change is accompanied by a change in voicing in the same segment (3-b). It is important to specify that the two changes happen in the same segment in order to prevent a change in voicing in one segment from having an effect on the continuancy of another segment. For now, the restriction to single segments is stipulated but will be motivated in section 3 .
a. $\quad \operatorname{Ident}($ cont $) \& \neg I \operatorname{dent}($ voice $)$
Assign a violation to an input-output pair violating Ident(cont) but not Ident(voice).
b. Ident(cont)\&Ident(voice)
Assign a violation to an input-output pair violating Ident(cont) and Ident(voice).

More generally, for any two features $F$ and $G$, constraints of the format $\operatorname{Ident}(F) \& \neg \operatorname{Ident}(G)$ and Ident(F)\&Ident(G) can be built (4). In section 3, I suggest a way to restrict the features that can interact in this type of constraints.
a. $\quad \operatorname{Ident}(\mathrm{F}) \& \neg \operatorname{Ident}(\mathrm{G})$
Assign a violation to an input-output segment pair violating $\operatorname{Ident}(\mathrm{F})$ but not $\operatorname{Ident}(\mathrm{G})$.
b. $\quad \operatorname{Ident}(\mathrm{F}) \& \operatorname{Ident}(\mathrm{G})$
Assign a violation to an input-output segment pair violating $\operatorname{Ident}(\mathrm{F})$ and $\operatorname{Ident}(\mathrm{G})$.

Local conjunctions of faithfulness constraints F\&F' have already been proposed to model synchronic chain shifts (Kirchner, 1996; Moreton \& Smolensky, 2002). The only innovation is in the possibility to conjoin faithfulness and anti-faithfulness constraints. $\neg \operatorname{Ident}(\mathrm{F})$ is an anti-faithfulness constraint because it penalizes a faithful input-output mapping (see Alderete, 2001 on anti-faithfulness). Anti-faithfulness constraints are a variety of faithfulness constraints because they evaluate input-output mappings.

The constraints in (4-a) and (4-b) can also be thought of as faithfulness constraints indexed to a particular phonological process affecting the same segment: $\operatorname{Ident}(\mathrm{F}) \& \neg \operatorname{Ident}(\mathrm{G})$ protects $\mathrm{F}$ just in case no phonological process has changed $\mathrm{G}$ and $\operatorname{Ident}(\mathrm{F}) \& \operatorname{Ident}(\mathrm{G})$ protects $\mathrm{F}$ just in case a phonological process has changed $\mathrm{G}$. In this sense, they are similar to Wolf's (2008) PREC constraints: these constraints assign violations of faithfulness depending on whether a phonological process has applied in a previous evaluation. An important difference has to do with the framework that is assumed: Wolf's (2008) system relies on a representation of the candidates evaluated by the grammar as chains whereas the current analysis is compatible with the classical OT conception of candidates as static phonological forms.

Table (5) shows how these constraints assign violations to the input-output segment pairs relevant for Campidanian Sardinian and how they compare to the simple Ident(cont) constraint. Ident(cont) assigns a violation mark to both pairs because both pairs involve a change in continuancy. Ident(cont)\& $\neg$ Ident(voice) assigns a violation mark to the pair $</ g /$, $[\gamma]>$ because this pair violates Ident(cont) but satisfies Ident(voice). Ident(cont)\&Ident(voice) assigns a violation mark to the pair $</ \mathrm{k} /$, $[\mathrm{\gamma}]>$ because this pair violates both Ident(cont) and Ident(voice).

$$
\begin{aligned}
& \text { Violation profiles of the two context-sensitive faithfulness constraints } \\
& \text { Ident(cont)\& } \neg \text { Ident(voice) } \quad \text { Ident(cont)\&Ident(voice) Ident(cont) } \\
& </ \mathrm{k} /,[\mathrm{\gamma}]> \\
& </ \mathrm{g} / \text {, }[\mathrm{\gamma}]>
\end{aligned}
$$

*

By the P-map, the hypothesis that lenition is less noticeable in the context of a change in voicing translates into the ranking in (6): the constraint penalizing a change in continuancy in the context of a change in voicing, Ident(cont)\&Ident(voice), is outranked by the constraint penalizing a change in continuancy alone, Ident(cont)\& $\neg$ Ident(voice).

(6) A change in continuancy is less noticeable in the context of a change in voicing: $\operatorname{Ident}($ cont $) \& \neg \operatorname{Ident}($ voice $) \gg \operatorname{Ident}($ cont $) \& I d e n t($ voice $)$ 
Campidanian Sardinian lenition can be derived by interleaving the markedness constraints responsible for voicing and lenition in the ranking in (6). The ranking in (7-a) derives intervocalic voicing. The ranking in (7-b) derives lenition conditioned on voicing.

OT ranking for Campidanian Sardinian

a. Intervocalic voicing $* \mathrm{VC}_{\text {[-voice] }} \mathrm{V} \gg \operatorname{Ident}($ voice)

b. Intervocalic voicing conditions lenition $* \mathrm{VC}_{\text {[-voice] }} \mathrm{V} \gg \mathrm{Ident}($ cont $) \& \neg \operatorname{Ident}($ voice $) \gg * \mathrm{VC}_{[\text {-cont] }} \mathrm{V} \gg \operatorname{Ident}($ cont $) \& I d e n t($ voice $)$

If the stop is underlyingly voiceless, intervocalic voicing is enforced through the ranking in (7-a). Once a change in voicing has been made, the constraint which is relevant to evaluate violations of faithfulness to continuancy is Ident(cont)\&Ident(voice). This constraint is ranked under $* \mathrm{VC}_{\text {[-cont] }} \mathrm{V}$. Therefore, the voicing change must be accompanied by a change in continuancy. If the stop is underlyingly voiced, nothing motivates a violation of Ident(voice). As a consequence, the constraint which is relevant to evaluate violations of faithfulness to continuancy is Ident(cont)\& $\neg$ Ident(voice). This constraint outranks $* \mathrm{VC}_{\text {[-cont] }} \mathrm{V}$. Therefore, lenition does not happen. The analysis derives the desired interaction between the two changes, where lenition applies only if voicing applies. The tableaux in (8) show more concretely how the analysis derives Campidanian Sardinian lenition.

Analysis of Campidanian Sardinian lenition

a. $/ \mathrm{k} / \rightarrow[\mathrm{y}]$

\begin{tabular}{|c|c|c|c|c|}
\hline /de kuat:ro/ & $* \mathrm{VC}_{\text {[-voice] }} \mathrm{V}$ & $\begin{array}{lll}\operatorname{Id}(\text { voice }) & \operatorname{Id}(\text { cont }) \& \\
& \neg \operatorname{Id}(\text { voice })\end{array}$ & $* \mathrm{VC}_{\text {[-cont] }} \mathrm{V}$ & $\begin{array}{l}\text { Id(cont)\& } \\
\operatorname{Id}(\text { voice })\end{array}$ \\
\hline dekuatiro & $* !$ & 1 & * & \\
\hline deguat:ro & & * & $* !$ & \\
\hline deyuat:ro & & * & & * \\
\hline
\end{tabular}

b.

\begin{tabular}{|c|c|c|c|c|}
\hline \multicolumn{5}{|c|}{$\rightarrow[\mathrm{g}]$} \\
\hline /de goma/ & $* \mathrm{VC}_{\text {[-voice] }} \mathrm{V}$ & $\begin{array}{c:c}\mathrm{Id}(\text { voice }) & \operatorname{Id}(\text { cont }) \& \\
& \neg \operatorname{Id}(\text { voice }\end{array}$ & $* \mathrm{VC}_{[- \text {cont] }} \mathrm{V}$ & $\begin{aligned} \operatorname{Id}(\text { cont }) \& \\
\operatorname{Id}(\text { voice })\end{aligned}$ \\
\hline degəma & & 1 & * & \\
\hline deуoma & & $* !$ & & \\
\hline
\end{tabular}

\section{Typological consequences}

By grounding PDEEs in perception, this account makes it possible to constrain the features that interact in these patterns and the domain of this interaction. This section discusses three predictions that are compatible with the perceptually-based account (the locality condition in section 3.1 and the one-dimension and monotonicity conditions in section 3.2) and evaluates them against the typology of PDEEs.

3.1 Locality condition The intuition behind the current proposal is that, in PDEEs, the second feature change is licensed in the context of another feature change because it can be perceived as a continuation of this change. For the second feature change to be perceived as a continuation of the first one, it is plausible that the two feature changes have to affect the same phonological entity, i.e. the same segment - assuming that features are properties of segments. This reasoning derives the locality condition in (9).

Locality condition

In PDEEs, the two feature changes happen on the same segment.

The locality condition seems to hold of many cases of PDEEs reported in the literature. For instance, all cases of saltatory alternations cited by Hayes \& White (2015) involve a single segment, except for the pattern of glottal epenthesis in Makassarese, where glottal epenthesis in word-final position is conditioned on vowel epenthesis: $/\{\mathrm{r} 1 \mathrm{~s}\} \# / \rightarrow[\{\mathrm{r} 1 \mathrm{~s}\} \mathrm{V}$ ?\#] $/ *[\{\mathrm{r} 1 \mathrm{~s}\} \mathrm{V \#}]$ but $/\{\mathrm{r} 1 \mathrm{~s}\} \mathrm{V \# /} \rightarrow[\{\mathrm{r} 1 \mathrm{~s}\} \mathrm{V \#}] / *[\{\mathrm{r} 1 \mathrm{~s}\} \mathrm{V} ? \#]$. However, Hayes \& White (2015:279) report that there is also a stress difference between the two types of cases: stress

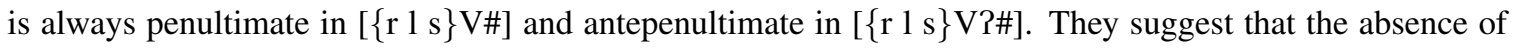


epenthesis after word-final lexical vowels could be motivated by a markedness constraint against a sequence containing a stressed vowel followed by a heavy syllable.

There are two well-known cases of PDEEs where the the licensing and licensed changes affect different (but adjacent) segments: Finnish assibilation and Sanskrit ruki (Kiparsky, 1982, 1993). In Finnish, assibilation $(/ \mathrm{t} / \mathrm{H} \rightarrow \mathrm{s}] / \mathrm{i})$ happens only before high vowels derived from underlyingly nonhigh vowels (/e/ $\rightarrow[i] / \#$ ). This gives rise to a saltatory alternation where word-final/te/ is realized as [si] (with raising and assibilation) but word-final /ti/ is realized as [ti] without any change. In Sanskrit, retroflexion after back segments [r u k] and [i] (/S/ $\rightarrow\left[{ }_{S}\right] /\left\{\mathrm{r} \mathrm{u} \mathrm{k} \mathrm{i}_{-}\right)$happens if the dental and the [r u k i] segment were not adjacent underlyingly but became adjacent in the surface form through vowel deletion (10-a) (vowel deletion is morphologically motivated: it is the realization of the zero grade of stems). Retroflexion does not happen in nonderived environments (10-b). This gives rise to a saltatory alternation where $/ \mathrm{uVs} /$ is realized as [us] (with vowel-deletion and s-retroflexion) but/us/ is realized as [us] without any change.

Sanskrit ruki

a. Assimilation after [ $\mathrm{r} \mathrm{u} \mathrm{k} \mathrm{i]} \mathrm{in} \mathrm{environments} \mathrm{derived} \mathrm{by} \mathrm{the} \mathrm{application} \mathrm{of} \mathrm{zero} \mathrm{grade} \mathrm{ablaut}$ uștá /uas-tál [uștá]/*[ustá] 'shone, dwelt'

b. No assimilation after [ $\mathrm{r} \mathrm{u} \mathrm{k} \mathrm{i]} \mathrm{in} \mathrm{non-derived} \mathrm{environments}$ pustaka [pustaka]/*[pustaka] 'book'

These cases can be analyzed as satisfying the strict locality condition in (9) if the input to the phonological grammar is assumed to include some phonetic detail. The assumption of a phonetically rich input is common in works following the program of phonetically-based phonology (see Steriade, 2000; Flemming, 2008) and McCarthy (2009) suggests that this is even a necessary requirement for analyses using the P-map: in order to compare the perceptual impact of an input-output change, the two representations (input and output) must be specified phonetically.

I illustrate how the analysis works with Sanskrit ruki. The proposal is the following: vowel deletion feeds retroflexion in (10-a) because it results in the creation of new formant closure transitions, different from the transitions in the input. This change affecting the consonant's closure transitions then licenses a total assimilation of the consonant. In order to formalize the present analysis, the formant realization of consonants must be represented in phonological representations. I propose to distinguish two dental sibilant allophones in terms of their closure properties. When preceded by a segment with a low F3 (i.e. a back segment $\left[\mathrm{r} \mathrm{u} \mathrm{k}^{2}\right.$ ), the allophone of [s] has a low F3 realization at its onset and the transition between this segment and [s] is characterized by a sharply rising F3. This allophone will be noted as [F3s], where [F3] denotes a low F3 realization at the onset of the consonant. When preceded by a segment that does not have a low F3, the F3 realization of the sibilant will not be as low and the F3 transition will not be as sharp. This allophone will be noted as $\left[{ }^{\mathrm{F} 3} \mathrm{~s}\right]$, where $\left[{ }^{\mathrm{F3}}\right]$ materialized as a high $\mathrm{F} 3$ realization at the onset of the consonant. The allophone $\left[{ }^{\mathrm{F} 3} \mathrm{~s}\right]$ is the default allophone because a dental consonant has a high F3 target. Hence, the form $/ \mathrm{ua}^{\mathrm{F} 3} \mathrm{~S}$-tá/ contains the default allophone $/{ }^{\mathrm{F} 3} \mathrm{~S} /$.

We are now in a position to be able to characterize the licensing change as a change affecting the closure properties of the dental sibilant. When the [a] preceding the dental sibilant in the input /ua ${ }^{\mathrm{F} 3}$-tá/ in (10-a) is deleted, the dental sibilant comes in contact with [u]. The underlying allophone $\left[{ }^{\mathrm{F} 3}\right.$ s $]$ with a high $\mathrm{F} 3$ realization is replaced with the allophone [F3s] with a low F3 realization through coarticulation with the preceding [u] (see Flemming, 2011 for evidence that coarticulation is part of the grammar). The change affecting the sibilant's closure transitions then feeds a total assimilation of the sibilant: [F3s] becomes the retroflex [F3s]. This second change is motivated by a markedness constraint against consonants with conflicting place cues (low F3 closure transitions vs. frication noise with a high center of gravity). This constraint can also be interpreted as a constraint disfavoring poor dental-retroflex contrasts, i.e. [F3s]-[F3s] contrasts that are not cued by distinct enough closure transitions. If the closure transition is already similar to that of a retroflex sibilant in the input, assimilation of the frication noise in the output is blocked because it represents a larger change comparatively.

Formally, the interaction of vowel deletion and retroflexion after $[\mathrm{r} \mathrm{u} \mathrm{k}]$ is derived with the markedness constraints in (11). Ablaut (11-a) regulates the alternation between full-grade and zero-grade ablaut. $* \mathrm{X}_{\mathrm{F} 3}{ }^{\mathrm{F} 3} \mathrm{C}$ in (11-b) is the markedness constraint that triggers the conditioning change: this constraint is responsible for

\footnotetext{
2 I leave aside [i]. See Flemming (2003:366-368) for a discussion of why [i] might trigger retroflexion.
} 
the lowering of the dental sibilant's F3 realization after segments with low F3 targets. ${ }_{\mathrm{F} 3 \mathrm{~S}}$ in (11-c) is the markedness constraint that triggers the second change (the full assimilation to a retroflex).

Markedness constraints needed to derive the Sankrit ruki

a. Ablaut

Assign a violation mark to a candidate with full-grade ablaut in a past participle.

b. $* \mathrm{X}_{\mathrm{F} 3}{ }^{\mathrm{F} 3} \mathrm{C}$

Assign a violation mark to a candidate containing a consonant with a high F3 onset-realization following a segment with a low F3 offset-realization.

c. * ${ }_{\mathrm{F} 3 \mathrm{~S}}$

Assign a violation mark to any dental sibilant realized with a low F3 onset-realization.

The faithfulness constraints in (12) are needed to derive the interaction of the two changes. $\mathrm{C}^{\text {clos }}$ is a variable that refers to $\mathrm{C}$ 's closure allophones, ${ }_{\mathrm{F} 3} \mathrm{C}$ and ${ }^{\mathrm{F} 3} \mathrm{C}$ in the present case. $\mathrm{C}^{\text {fric }}$ is a variable that refers to different ways of realizing a consonant's frication noise, here as a dental frication noise [s] (with a high center of gravity) or as retroflex frication noise [s] (with a lower center of gravity). $\operatorname{Ident}\left(\mathrm{C}^{\text {clos }}\right)$ in $(12-\mathrm{a})$ penalizes the mapping from $/{ }^{\mathrm{F} 3} \mathrm{~S} /$ to $\left[\mathrm{F}_{3} \mathrm{~S}\right]$. It conflicts with ${ }^{*} \mathrm{X}_{\mathrm{F} 3}{ }^{\mathrm{F3}} \mathrm{C}$ in (11-b). $\operatorname{Ident}\left(\mathrm{C}^{\text {fric }}\right) \& \neg \operatorname{Ident}\left(\mathrm{C}^{\text {clos }}\right)$ in (12-b) and $\operatorname{Ident}\left(\mathrm{C}^{\text {fric }}\right) \& \operatorname{Ident}\left(\mathrm{C}^{\text {clos }}\right)$ in $(12-\mathrm{c})$ are the faithfulness constraints that derive the interaction between the two changes affecting the sibilant's closure transitions and frication noise.

Faithfulness constraints needed to derive the Sankrit ruki

a. $\operatorname{Ident}\left(\mathrm{C}^{\text {clos }}\right)$

Assign a violation mark for any input-output consonant pairs such that $\mathrm{C}^{\text {clos }}{ }_{\mathrm{I}} \neq \mathrm{C}^{\text {clos }}{ }_{\mathrm{O}}$.

b. $\quad \operatorname{Ident}\left(\mathrm{C}^{\text {fric }}\right) \& \neg \operatorname{Ident}\left(\mathrm{C}^{\text {clos }}\right)$

Assign a violation mark for any input-output consonant pairs such that $\mathrm{C}^{\text {fric }}{ }_{\mathrm{I}} \neq \mathrm{C}_{\mathrm{O}}^{\text {fric }}$ and $\mathrm{C}^{\mathrm{clos}}{ }_{\mathrm{I}}$ $=\mathrm{C}^{\text {clos }} \mathrm{O}$

c. $\operatorname{Ident}\left(\mathrm{C}^{\text {fric }}\right) \& \operatorname{Ident}\left(\mathrm{C}^{\text {clos }}\right)$

Assign a violation mark for any input-output consonant pairs such that $\mathrm{C}_{\mathrm{I}}^{\mathrm{fric}} \neq \mathrm{C}_{\mathrm{O}}^{\text {fric }}$ and $\mathrm{C}^{\text {clos }}$ $\neq \mathrm{C}^{\text {clos }} \mathrm{O}$

The ranking in (13) derives the ruki pattern.

Constraint ranking deriving the ruki pattern

Ablaut, $* \mathrm{X}_{\mathrm{F} 3}{ }^{\mathrm{F3}} \mathrm{C} \gg \operatorname{Ident}\left(\mathrm{C}^{\text {clos }}\right)$, $\operatorname{Ident}\left(\mathrm{C}^{\text {fric }}\right) \& \neg \operatorname{Ident}\left(\mathrm{C}^{\text {clos }} \gg *_{\mathrm{F} 3 \mathrm{~S}} \gg \operatorname{Ident}\left(\mathrm{C}^{\text {fric }}\right) \& \operatorname{Ident}\left(\mathrm{C}^{\text {clos }}\right)\right.$

Ablaut and $* \mathrm{X}_{\mathrm{F} 3}{ }^{\mathrm{F} 3} \mathrm{C}$ outrank the faithfulness constraint requiring segment's closure transitions to be identical in the input and in the output, $\operatorname{Ident}\left(\mathrm{C}^{\text {clos }}\right)$. This motivates the licensing change. The ranking $*_{\mathrm{F} 3 \mathrm{~S}}$ $\gg \operatorname{Ident}\left(\mathrm{C}^{\text {fric }}\right) \& \operatorname{Ident}\left(\mathrm{C}_{\text {clos }}\right)$ licenses a further change affecting the frication noise in case the closure transitions have been changed. When the closure transitions have not been changed, the ranking $\operatorname{Ident}\left(\mathrm{C}^{\text {fric }}\right) \& \neg \operatorname{Ident}\left(\mathrm{C}_{\text {clos }}\right) \gg *_{\mathrm{F} 3 \mathrm{~S}}$ prevents the assimilation from happening.

The tableaux in (14) show how the analysis derives retroflexion in phonologically-derived environments (14-a) and blocking in nonderived environments (14-b). The analysis in (14-a) is simplified to focus on the phonologically-derived environment effect: as is, this analysis does not derive the assimilation of [t] to the preceding retroflex $\left[\mathrm{s}_{\mathrm{S}}\right]$ in [ $\left.\mathrm{u}_{\mathrm{F} 3} \mathrm{~s}_{\mathrm{S}}\right]$. Deriving this assimilation would require additional constraints.

Analysis of Sanskrit ruki

a. $\quad / \mathrm{ua}^{\mathrm{F}}{ }_{\mathrm{n}}$-tál $\rightarrow\left[\mathrm{u}_{\mathrm{F} 3}\right.$ stá $]$

\begin{tabular}{|c|c|c|c|c|c|}
\hline ua ${ }^{\mathrm{F} 3} \mathrm{~N}_{\mathrm{n}}$-tá & $\begin{aligned} \text { Ablaut } \\
\\
\text { । }\end{aligned}$ & $* \mathrm{X}_{\mathrm{F} 3}{ }^{\mathrm{F} 3} \mathrm{C}$ & $\begin{array}{c:c}\operatorname{Id}\left(C^{\text {clos }}\right) & \operatorname{Id}\left(C^{\text {fric }}\right) \& \\
& \neg \operatorname{Id}\left(C_{\text {clos }}\right)\end{array}$ & $*_{\mathrm{F} 3 \mathrm{~S}}$ & $\begin{array}{l}\operatorname{Id}\left(C^{\text {fric }}\right) \& \\
\operatorname{Id}\left(C_{\text {clos }}\right)\end{array}$ \\
\hline $\mathrm{ua}^{\mathrm{F} 3}$ stá $_{n}$ & $* !$ & & 1 & & \\
\hline $\mathrm{u}^{\mathrm{F} 3}$ stá & I & $* !$ & I & & \\
\hline u u 3 Stá & $\begin{array}{l}1 \\
1\end{array}$ & & $\begin{array}{l}1 \\
1\end{array}$ & $* !$ & \\
\hline u usstá & । & & $*$ & & * \\
\hline
\end{tabular}

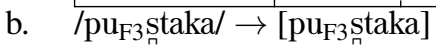




\begin{tabular}{|c|c|c|c|c|}
\hline pu $_{\text {F3staka }}$ & $* \mathrm{X}_{\mathrm{F} 3}{ }^{\mathrm{F} 3} \mathrm{C}$ & $\begin{array}{c:c}\operatorname{Id}\left(C^{\text {clos }}\right) & \operatorname{Id}\left(C^{\text {fric }}\right) \& \\
& \neg \operatorname{Id}\left(C_{\text {clos }}\right)\end{array}$ & $*_{\mathrm{F} 3 \mathrm{~S}}$ & $\begin{array}{l}\operatorname{Id}\left(C^{\text {fric }}\right) \& \\
\operatorname{Id}\left(C_{\text {clos }}\right)\end{array}$ \\
\hline pu pus $_{\mathrm{F}}$ staka & & 1 & $*$ & \\
\hline $\mathrm{pu}_{\mathrm{F} 3 \mathrm{staka}}$ & & $* !$ & & \\
\hline
\end{tabular}

This analysis straightforwardly extends to morphologically-derived environments. In Finnish and Sanskrit, assibilation and retroflexion are also fed by morphological concatenation (e.g. Finnish $/ \mathrm{t}-\mathrm{i} / \rightarrow$ [si] and Sanskrit /u-s/ $\rightarrow$ [us]). This is explained as follows: once phonological forms are assumed to be phonetically rich, morphological concatenation may have subtle phonological effects (for instance, changing the realization of a stem-final consonant before a suffix) and these subtle phonological effects may license further phonological changes (for instance, changing the manner or place of articulation of the stem-final consonant before a suffix), according to the logic of PDEEs.

To summarize, the perceptually-based analysis is able to make sense of the locality condition on the domain of features interacting in PDEE. Violations of the strict locality condition illustrated by Finnish assibilation and Sanskrit ruki can be accounted for for free, since the P-map assumes that the phonological input is phonetically rich. This assumption also makes it possible to extend the analysis to morphologicallyderived environments.

3.2 One-dimension and monotonicity conditions If PDEEs are based in perception, it is plausible that not all feature changes can interact but only feature changes that add up along a common perceptual dimension. This derives the two conditions in (15-a) and (15-b).

a. One-dimension condition

The two feature changes happen along the same perceptual dimension.

b. Monotonocity condition

The second change is a continuation of the first change along the relevant dimension.

The one-dimension condition and the monotonicity condition seem to be satisfied in many cases of PDEEs reported in the literature. This is somewhat surprising if there is no constraint on the features that can interact in PDEEs. Sections 3.2.1, 3.2.2 and 3.2.3 describe PDEE patterns that are likely to satisfy these conditions. Section 3.2.4 describes two potentially problematic cases.

3.2.1 Consonant duration Several cases of PDEEs may be analyzed as involving two changes affecting the duration of a consonant in a monotonic way. For instance, the voicing conditions lenition pattern attested in Campidanian Sardinian (see section 1.1) and Manga Kanuri (Hayes \& White, 2015:278) satisfy these conditions: (i) voicing and lenition both affect closure duration and (ii) lenition involves a further step of shortening of the closure after voicing: $\operatorname{dur}(\mathrm{k})>\operatorname{dur}(\mathrm{g})>\operatorname{dur}(\mathrm{\gamma})$ (see Lisker, 1957 for evidence for $\operatorname{dur}(\mathrm{k})>\operatorname{dur}(\mathrm{g})$ in English and Marotta, 2001:32 for evidence for $\operatorname{dur}(\mathrm{g})>\operatorname{dur}(\mathrm{y})$ in Tuscan Italian spoken in Pisa). Campidanian Sardinian has another PDEE, where degemination of voiced geminate obstruents [b: d: g:] conditions lenition to [ $\beta$ б y] (voiced singleton obstruents [b d g] remain intact). This pattern also satisfies the one-dimension and monotonicity conditions. Lenition involves a further step of reduction of the closure duration after degemination: $\operatorname{dur}(\mathrm{g}:)>\operatorname{dur}(\mathrm{g})>\operatorname{dur}(\mathrm{y})$.

Finnish gradation (Kiparsky, 1993:282-284) may also be analyzed as involving two changes affecting consonant duration monotonically. In Finnish, when an underlying geminate is in the onset of an open syllable underlyingly ${ }^{3}$ but appears in the onset of a closed syllable as a result of a phonological process (e.g. wordfinal vowel deletion) or morphological concatenation, the geminate is degeminated (16-a). The consonant $\mathrm{C}$ ends up in a closed syllable in (16-a) because of a process deleting word-final [e] in polysyllables. However, a geminate consonant may appear in the onset of a nonderived closed syllable (16-b).

Finnish gradation (Kiparsky, 1993:283)

a. Geminates that are in the onset of derived closed syllables surface as singletons /vait:eCe/ [va:teC]

3 Given the assumption that the input to the phonological grammar is phonetically rich, this is not problematic to have syllable structure in the input. 
b. Geminates that are underlyingly in the onset of closed syllables surface as geminates /sit:en/ [sit:en] 'then'

In the present analysis, this pattern may be analyzed as follows. In the phonetic realization of the input, geminates are shorter in the onset of nonderived closed syllables than in the onset of nonderived open syllables, due to compression (see for instance Katz, 2012 on compression effects). When a geminate in an underlyingly open syllable ends up in a closed syllable in the output, it is shortened a little bit to satisfy a markedness constraint against maximally long geminates in closed syllables. This shortening then licenses a further step of shortening, i.e. a full degemination. This account predicts that geminates should be shorter in closed syllables than in open syllables in Finnish: $\operatorname{dur}\left(\mathrm{t}_{\text {OpenSyll }}\right)>\operatorname{dur}\left(\mathrm{t}_{\text {ClosedSyll }}\right)>\operatorname{dur}(\mathrm{t})$. I leave the test of this prediction for future work.

3.2.2 Vowel duration There are a number of cases reported in the literature where vowel destressing conditions reduction (Romanian, Western Armenian, Palauan, Yakan; see Khanjian, 2009; Steriade, 2015). For instance, in Romanian, stem low vowels which lose stress under affixation are reduced to $[\Lambda]$ (17-a) whereas low vowels which are unstressed in the base are not reduced under affixation (17-b). As a consequence, $\left[\right.$ 'a] alternates with $[\Lambda]$ whereas [a] does not. ${ }^{4}$ I assume that the input to derivative formation bears stress, although stress is predictable in the language. This is consistent with the general hypothesis that the phonological input is phonetically detailed. This assumption is necessary to derive the Romanian pattern: if the input does not carry stress, then there is no way to distinguish (17-a) and (17-b) (see Rasin, 2016:23-24).

Romanian vowel reduction

a. Base low vowels which lose stress under affixation are raised barbă 'beard' /'barbs/ [b'arbs] 'beard'

/'barbs-'os/ [bsr'bos] 'bearded'

b. Low vowels that are not stressed in the base are not raised under affixation masină 'machine' /ma'fin $/$ [ma'fin $\Lambda$ 'machine' /ma'fins-'utss/ [mafin'utss] 'machin-DIM'

The two changes (destressing followed by raising) satisfy the one-dimension and monotonicity conditions: destressing reduces the duration of the vowel, and raising reduces it even more. This is shown in Figure 2 for Romanian, where $\operatorname{dur}($ 'a) $>\operatorname{dur}(\mathrm{a})>\operatorname{dur}(\Lambda)$ (data from a female Romanian native speaker).

Tiberian Hebrew has a pattern where vowel lengthening conditions lowering: underlying long high vowels /i: u:/ remain high but underlying short high vowels /i u/ which are lengthened contextually (e.g. under stress or in pre-guttural position) are also lowered and realized as [e: o:] (Prince, 1975 via Lubowicz, 1998). This PDEE is also likely to satisfy the one-dimension and monotonicity conditions:

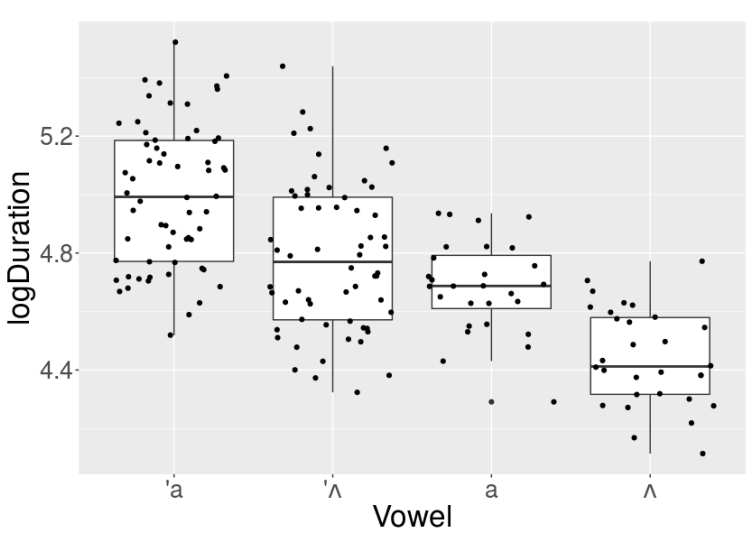

Figure 2: Romanian vowel duration lower vowels are generally longer than higher vowels (Lehiste, 1970; Escudero et al., 2009) and therefore lowering can be analyzed as further step of lengthening following the contextual lengthening caused by stress or by a following guttural: $\operatorname{dur}(\mathrm{i})<$ $\operatorname{dur}(\mathrm{i}:)<\operatorname{dur}(\mathrm{e}:)$.

The lengthening conditions diphthongization pattern in Slovak might be analyzed similarly, if diphthongs are longer than long vowels in this language. In Slovak, underlyingly short mid vowels /e o/ are diphthongized and realized as [ie uo] in morphological environments where other vowels are lengthened but underlyingly long /e: o:/ are not diphthongized (Kenstowicz \& Rubach, 1987). The two changes (lengthening followed by

\footnotetext{
4 I am grateful to Donca Steriade for her permission to use this material in this paper.
} 
diphthongization) satisfy the one-dimension condition and monotonocity condition if $d u r(\mathrm{e})<\operatorname{dur}(\mathrm{e}:)<$ $\operatorname{dur}($ ie). Unfortunately, there is no study comparing directly the duration of long vowels and diphthongs (see Král' \& Sabol, 1989; Beňuš \& Mády, 2012 for information on vowel duration in Slovak). ${ }^{5}$

3.2.3 Consonant frequency Does the Sanskrit pattern discussed in section 3.1 satisfy the one-dimension condition and the monotonocity condition? The two changes involved in the Sanskrit ruki seem to affect different dimensions, i.e. the closure transitions into the sibilant and the sibilant's frication noise. This is potentially problematic for the one-dimension condition in (15-a). However, Kingston et al. (2008) suggest that rather than paying attention to every individual property in the acoustic signal, the auditory system might perceive acoustically related cues as a single 'intermediate perceptual property'. Specifically, they found evidence for the perceptual integration of multiple properties associated with low frequency spectral continuity into a single 'low frequency' property ( $\mathrm{f} 0$ and $\mathrm{F} 1$ ). The same notion of integrated frequency may be involved in Sanskrit. Coarticulation lowers the F3 realization of the sibilant at vowel offset. Assimilation lowers the center of gravity of the sibilant. Understood this way, the two changes also satisfy the monotonicity condition: they both involve lowering along the integrated frequency dimension.

A similar analysis may be proposed for other patterns where coarticulation of underlyingly nonadjacent segments feeds a total assimilation of one of the two segments to the other (e.g. Finnish assibilation: Kiparsky, 1993, Polish spirantization: Rubach, 1984, Romanian velar palatalization: Steriade, 2008). In these languages, a consonant that comes in contact with a front segment through a phonological process or through morphological concatenation becomes more front (assibilates, spirantizes, or palatalizes) but a consonant that is underlyingly adjacent to a front segment remains intact. Coarticulation with the front vowel results in an increase of the F2 realization of the consonant at vowel onset. Assibilation, spirantization and palatalization raise the frequency of the consonant's center of gravity. In total, the two changes involve a general increase of the consonant's frequency.

3.2.4 Potentially problematic cases However, not all cases of PDEEs reported in the literature seem to satisfy the two conditions (15-a) and (15-b). In particular, there are two productive cases of PDEEs that are potentially problematic: German spirantization (Ito \& Mester, 2003) and Japanese nasalization (Ito \& Mester, 1997). Standard German has a general process of word-final devoicing. In word-final position after atonic [I], underlying /g/ is not only devoiced but also spirantized and palatalized (18-a) whereas underlying $/ \mathrm{k} /$ remains intact (18-b). Japanese has a general process by which the initial consonant of the noninitial part of a compound is voiced. This process is known as rendaku. When the underlying consonant is voiceless, it is not only voiced but also nasalized (19-a). However, when the underlying consonant is already voiced, nasalization is only optional (19-b).

\section{Standard German spirantization}

a. $/ \mathrm{g} /$ is devoiced, spirantized and palatalized in word-final position after atonic [I] Koenig /'kønig/ ['køniç] 'king'

b. $/ \mathrm{k} /$ remains intact in coda position after atonic $[\mathrm{I}]$ Plastik /'plastık/ ['plastık] 'plastic'

Japanese rendaku

a. Underlying $/ \mathrm{k} /$ voices and nasalizes

/yuki-kuni/ [yukiguni]/*[yukiguni] 'snow country'

b. Underlying/g/ optionally nasalizes

/niwa-geta/ [niwayeta]/[niwageta] 'garden clogs'

These two cases are problematic for the one-dimension and monotonicity conditions because it is unclear along which perceptual dimension spirantization could be conceived as a continuation of devoicing and along which perceptual dimension nasalization could be conceived as a continuation of voicing.

Assuming that the sample of languages surveyed in section 3 is representative of the actual typology

\footnotetext{
5 An alternative analysis may be possible for Slovak: if morphological environments usually analyzed as triggering lengthening in Slovak are reanalyzed as triggering diphthongization, the absence of diphthongization for nonmid vowels /i u a/ might be due to markedness constraints against high diphthongs and low diphthongs. This analysis would imply that the Slovak pattern is not a PDEE.
} 


\begin{tabular}{|c|c|c|c|}
\hline Pattern & Dimension & Monotonicity & Language \\
\hline Voicing feeds lenition & C-duration & shortening & $\begin{array}{l}\text { Campidanian Sardinian } \\
\text { Manga Kanuri }\end{array}$ \\
\hline Degemination feeds lenition & C-duration & shortening & Campidanian Sardinian \\
\hline Compression feeds degemination & C-duration & shortening & Finnish gradation \\
\hline Destressing feeds reduction & V-duration & shortening & $\begin{array}{l}\text { Romanian } \\
\text { Armenian } \\
\text { Palauan } \\
\text { Yakan }\end{array}$ \\
\hline Lengthening feeds lowering & V-duration & lengthening & Tiberian Hebrew \\
\hline Half-retroflexion feeds retroflexion & C-frequency & lowering & Sanskrit ruki \\
\hline Fronting feeds assibilation & $\mathrm{C}$-frequency & raising & Finnish \\
\hline Fronting feeds spirantization & $\mathrm{C}$-frequency & raising & Polish \\
\hline Fronting feeds palatalization & $\mathrm{C}$-frequency & raising & Romanian \\
\hline Devoicing feeds spirantization & ? & $?$ & German \\
\hline Voicing feeds nasalization & ? & ? & Japanese rendaku \\
\hline
\end{tabular}

Table 1: Survey of PDEEs

of PDEEs, the one-dimension and monotonicity conditions on feature interactions in PDEEs should be considered as tendencies rather than as strong universals: 13 out of the 15 patterns mentioned in this section likely satisfy these conditions (see Table 1). It is unclear yet how unconstrained theories like Hayes and White's (2015) account can derive these tendencies.

\section{Conclusion}

This paper proposed that PDEEs follow from the hypothesis that the input-output distance is perceived logarithmically: this predicts that a feature change may be less salient perceptually and therefore represent a smaller violation of faithfulness if accompanied by another feature change. This theory has two desirable consequences: it reconciles the analysis of PDEEs with the idea of a minimal input-output modification bias and it derives a number of perceptual constraints on the features that can interact in PDEEs, therefore providing a restrictive account of the typology.

\section{References}

Alderete, John (2001). Dominance effects as transderivational anti-faithfulness. Phonology 18, 201-253.

Beňuš, Štefan \& Katalin Mády (2012). Stress and phonemic length in the perception of Slovak vowels. Proceedings of the 6th Speech Prosody Conference.

Bolognesi, Roberto (1998). The phonology of Campidanian Sardinian: A unitary account of self-organizing structure. Holland Academics, The Hague.

Burzio, Luigi (2000). Cycles, non-derived-environment-blocking, and correspondence. Dekkers, Joost, Frank van der Leeuw, \& Jeroen van de Weijer (eds.), Optimality theory: Phonology, syntax, and acquisition, Cambridge University Press, Cambridge.

Chomsky, Noam \& Morris Halle (1968). The sound patterns of English. MIT Press, Cambridge.

Escudero, Paola, Paul Boersma, Andréia Schurt Raubert \& Ricardo A. H. Bion (2009). A cross-dialect acoustic description of vowels: Brazilian and European Portuguese. Journal of the Acoustical Society of America 126, 13791393.

Flemming, Edward (2003). The relationship between coronal place and vowel backness. Phonology 20, 335-373.

Flemming, Edward (2008). The Realized Input. Ms.

Flemming, Edward (2011). The grammar of coarticulation. Embarki, M. \& C. Dodane (eds.), La Coarticulation: Indices, Direction et Representation.

Hayes, Bruce \& James White (2015). Saltation and the P-map. Phonology 32, 267-302.

Ito, Junko \& Arnim Mester (1997). Correspondence and compositionality: the ga-gyõ variation in Japanese phonology. Rocca, Iggy (ed.), Derivations and constraints in phonology, Clarendon, Oxford, 419-462. 
Ito, Junko \& Arnim Mester (2003). On the sources of opacity in OT: Coda processes in German. Féry, Caroline \& R. van de Vijver (eds.), The Syllable in Optimality Theory, Cambridge University Press, Cambridge, 271-303.

Katz, Jonah (2012). Compression effects in English. Journal of Phonetics 40, 390-402.

Kenstowicz, Michael \& Jerzy Rubach (1987). The phonology of syllabic nuclei in slovak. Language 63, $463-497$.

Khanjian, Hrayr (2009). Stress dependent vowel reduction. Proceedinds of the Berkeley Linguistic Society, Berkeley Linguistic Society \& Linguistic Society of America, vol. 35, 178-189.

Kingston, John, Randy L. Diehl, C. J. Kirck \& W. A. Castleman (2008). On the internal perceptual structure of distinctive features: The [voice] contrast. Journal of Phonetics 36, 28-54.

Kiparsky, Paul (1973). Phonological representations. Fujimura, Osamu (ed.), Three Dimensions of Linguistic Theory, TEC Company, Tokyo, Japan, 1-135.

Kiparsky, Paul (1982). Lexical Morphology and Phonology. of Korea, The Linguistic Society (ed.), Linguistics in the Morning Calm, Hanshin Publishing Company, Seoul, Korea, 3-91.

Kiparsky, Paul (1993). Blocking in nonderived environments. Hargun, Sharon, \& Ellen M. Kaisse (eds.), Phonetics and phonology 4: Studies in lexical phonology, Acamedic Press, San Diego, 277-313.

Kirchner, Robert (1996). Synchronic chain shifts in Optimality Theory. Linguistic Inquiry 27, 341-350.

Kisseberth, Charles W. (1972). Cyclical Rules in Klamath Phonology. Linguistic Inquiry 3, 3-33.

Král', Ábel \& Ján Sabol (1989). Fonetika a Fonologia. Slovenské pedagogické nakladatel'stvo, Bratislava.

Lehiste, Ilse (1970). Suprasegmentals. The MIT Press, Cambridge.

Lisker, Leigh (1957). Closure Duration and the Intervocalic Voiced-Voiceless Distinction in English. Language 33:1, 44-55.

Lubowicz, Anna (1998). Derived environment effects in OT. ROA.

Marotta, Giovanna (2001). Non solo spiranti. la 'gorgiana toscana' nel parlato di pisa. L'Italia dialettale: rivista di dialettologia italiana 62, 27-60.

McCarthy, John (2003). Comparative markedness. Theoretical Linguistics 29, 1-51.

McCarthy, John (2009). The P-Map in Harmonic Serialism. Linguistics Department Faculty Publication Series 83.

Moreton, Elliott \& Paul Smolensky (2002). Typological consequences of local constraint conjunction, Cascadilla Press, Cambridge: MA.

Prince, Alan (1975). The Phonology and Morphology of Tiberian Hebrew. Ph.D. thesis, MIT.

Prince, Alan \& Paul Smolensky (1993). Optimality Theory: Constraint interaction in generative grammar. Rutgers Center for Cognitive Science, Rutgers University, New Brunswick, NJ.

Rasin, Ezer (2016). Morpheme structure constraints and blocking in nonderived environments. Ms.

Rubach, Jerzy (1984). Cyclic and Lexical Phonology: The Structure of Polish. Foris, Dordrecht.

Steriade, Donca (2000). Paradigm uniformity and the phonetics-phonology boundary. Broe, Michael B. \& Janet B. Pierrehumbert (eds.), Papers in Laboratory Phonology V: acquisition and the lexicon, Cambridge University Press, Cambridge.

Steriade, Donca (2008). Unpublished lecture notes. Ms.

Steriade, Donca (2009). The phonology of perceptibility effects: the P-map and its consequences for constraint organization. Hanson, K. \& Sharon Inkelas (eds.), The nature of the word: Studies in honor of Paul Kiparsky, MIT Press, Cambridge, MA, 151-179.

Steriade, Donca (2015). Unpublished lecture notes. Ms.

White, James (2013). Bias in Phonological Learning: Evidence from Saltation. Ph.D. thesis, UCLA.

White, James (2014). Evidence for a learning bias against saltatory phonological alternations. Cognition 130, 96-115.

Wolf, Matthew (2008). Optimal interleaving: serial phonology-morphology interaction in a constraint-based model. Ph.D. thesis, University of Massachusetts, Amherst. 